\title{
Contribuições de atividades prático- experimentais para a formação de professores: reflexões a partir de um projeto de iniciação à docência em biologia
}

Tatiana Galieta

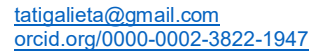
Orcid.org/0000-0002-3822-1947 (UERJ), São Gonçalo, RJ, Brasil

\section{RESUMO}

O caráter experimental da educação científica é um traço distintivo das demais áreas. As atividades prático-experimentais são utilizadas em aulas de Ciências para que estudantes da educação básica compreendam aspectos da natureza da Ciência, exercitem o raciocínio lógico e desenvolvam habilidades cognitivas relacionadas aos conhecimentos científicos. Neste trabalho realizamos uma avaliação das contribuições das atividades práticoexperimentais elaboradas e executadas por licenciandos em Ciências Biológicas para o processo de ensino-aprendizagem na prática da docência e para a formação inicial dos futuros professores. O cenário investigado foi o de um Subprojeto de Biologia da PIBIDCAPES cujas ações foram desenvolvidas em um colégio estadual do RJ com a participação de dez bolsistas no ano de 2017. As avaliações das atividades foram feitas por meio de três instrumentos: avaliações das atividades (presentes no relatório coletivo anual), reflexões presentes em textos acadêmicos (apresentados em eventos científicos) e questionário estruturado (respondido pelos bolsistas após um ano e meio do encerramento das atividades). Foram elaboradas 15 atividades, sendo a maioria de demonstração e verificação. Concluiu-se que elas, apesar de não terem contemplado ações investigativas, foram essenciais para a reflexão sobre o papel da experimentação no ensino de Ciências e na formação inicial dos futuros professores de Ciências e Biologia.

PALAVRAS-CHAVE: Atividades prático-experimentais. Formação inicial. Ensino de Ciências e Biologia. 


\section{INTRODUÇÃO}

Aulas de Ciências e Biologia possuem como objeto de ensino conteúdos, muitas das vezes, abstratos que remontam conhecimentos produzidos a partir de experimentos científicos. Assim, uma de suas características distintivas passou a ser a realização de atividades prático-experimentais de caráter didático. No entanto, a preparação dos futuros professores de Ciências e Biologia em cursos de licenciatura nem sempre promove reflexões acerca dos usos dessas atividades no que diz respeito ao desenvolvimento da linguagem científica, à natureza da Ciência e à compreensão das relações entre Ciência, Tecnologia e Sociedade (CTS), aspectos essenciais para uma alfabetização científica ampliada (AULER; DELIZOICOV, 2001).

A experimentação consiste em um dos mais importantes aspectos no processo de ensino-aprendizagem de Ciências e Biologia, como de outros ramos das Ciências da Natureza, devido à natureza do conhecimento específico desta área. Notavelmente, as atividades do tipo prático-experimental proporcionam a retomada, por parte dos educadores e dos alunos participantes, de elementos de uma experiência relacionada à corroboração de uma teoria, ou seja, elas têm como um de seus objetivos "aproximar a ciência escolar da ciência dos cientistas" (MUNFORD; LIMA, 2007, p.16).

A ênfase na experimentação na educação científica iniciou-se a partir da criação do Instituto Brasileiro de Ciência e Cultura (IBECC) que tinha como principal objetivo "promover a melhoria na formação científica dos alunos que ingressariam nas instituições de ensino superior contribuindo de forma significativa com o desenvolvimento nacional" (BARRA; LORENZ, 1986, p. 1971). A partir da década de 1950, a reforma curricular iniciada nos Estados Unidos, e que traduzia este objetivo na produção de materiais nos quais a ênfase estava na experimentação e na vivência do "método científico", chega ao Brasil por meio da implantação de modelos norte-americanos (como o BSCS - Biological Sciences Curriculum Study). Posteriormente, com a criação dos Centros de Ciências pelo então Ministério da Educação e Cultura (MEC), na década de 1960, pesquisadores brasileiros passaram a produzir e distribuir materiais didáticos para a realização de atividades de laboratório. Selles (2008) aponta as consequências deste movimento e ressalta que a experimentação como prática pedagógica além de ter trazido alguns equívocos (como as noções de que o conhecimento produzido pela ciência é resultante de uma série de passos sistematizados e de que o papel da escola era formar "pequenos cientistas") também não alcançou o êxito esperado por motivos às vezes relacionados à própria formação dos professores (aqueles que vivenciaram a tradição da pesquisa acabavam por reproduzir esta perspectiva para a sala de aula, enquanto outros que não vivenciaram a cultura científica acabavam por organizar aulas demonstrativas sem espaço para a argumentação).

Considerando este contexto histórico de inserção da experimentação no ensino de Ciências, percebemos que as atividades prático-experimentais têm assumido diferentes finalidades e têm sido executadas de diferentes maneiras, sendo objeto de estudo de pesquisadores da área de educação em Ciências. Santos (2001) realizou uma pesquisa de revisão bibliográfica que buscou caracterizar a produção acadêmica relacionada ao tema no ensino de ciências (somente no segundo segmento do ensino fundamental) em dissertações e teses 
entre 1972 e 1995. O autor localizou 12 trabalhos, tendo predomínio a área de Física, com atividades que ocorreram na sala de aula convencional, em sua maioria, e com maior incidência do uso de materiais de baixo custo, em detrimento de materiais exclusivamente industrializados. Além disso, o autor analisou os aspectos didáticos específicos das atividades experimentais e, entre seus resultados, destacamos a abordagem de fenômenos ou de conceitos nas atividades e o tipo de atividade experimental. A maior parte dos trabalhos "apresentam procedimentos com características típicas de uma abordagem centrada em conceitos isolados" (SANTOS, 2001, p. 66). Quanto ao tipo de atividade, "a maioria apresenta procedimentos de redescoberta, com base em um roteiro instrucional do tipo receituário" (p. 67).

Em uma pesquisa recente, Prado e Wesendonk (2019) fizeram uma revisão do tema em trabalhos publicados nas atas de cinco edições do ENPEC (Encontro Nacional de Pesquisa em Educação em Ciências) publicadas entre 2009 e 2017. As autoras localizaram 113 trabalhos e os organizaram em seis categorias relacionadas aos tipos de abordagens de atividades experimentais e seus objetivos, a saber: 1. A experimentação é utilizada com o objetivo de demonstrar/verificar/ilustrar um elemento do campo conceitual em estudo/relacionar a teoria com a prática (29 trabalhos); 2. A experimentação é utilizada com o objetivo de investigar/confrontar ideias/auxiliar na compreensão sobre como fazer Ciências (49 trabalhos); 3. A experimentação é utilizada com o objetivo de problematizar e/ou introduzir um determinado elemento do campo conceitual em estudo (19 trabalhos); 4. A experimentação é utilizada com o objetivo de aproximar os elementos do campo conceitual de uma determinada disciplina científica ao cotidiano dos alunos (31 trabalhos); 5 . A experimentação é utilizada com o objetivo de motivar e/ou efetivar a aprendizagem dos alunos sobre determinado elemento do campo conceitual em estudo (57 trabalhos); e 6. A experimentação é utilizada com o objetivo de auxiliar na compreensão de como a Ciência é construída e se desenvolve (9 trabalhos). Apesar de haver o destaque da categoria 5, as autoras apontam que os trabalhos situados nas demais categorias também estão associados a ela uma vez que destacam a "dimensão de motivar e de despertar o interesse dos alunos mediante a utilização de experimentações" (PRADO; WESENDONK, 2019, p. 161). Os resultados da revisão indicam que o tema tem sido pesquisado na área de Educação em Ciências, porém é destacada a necessidade de que os professores reflitam sobre os objetivos da experimentação que estão sendo contemplados em suas atividades didáticas.

A diversidade de atividades tem sido tradicionalmente mapeada por autores da área, e alguns têm buscado diferenciar conceitualmente cada uma delas, seja classificando-as em atividades práticas, experimentais e/ou laboratoriais (laboratório de pesquisa científica e laboratório didático) e, assim, tendo como foco as terminologias utilizadas (conforme encontramos em HODSON, 1988; VALADARES, 2006), seja avaliando suas finalidades nas aulas de ciências (ARRUDA; LABURÚ, 2005; ROSITO, 2008). Na próxima seção são retomados alguns dos artigos que discutem as finalidades de atividades práticas e/ou experimentais em aulas de Ciências. 


\section{ATIVIDADES PRÁTICAS E EXPERIMENTAIS: FINALIDADES NO ENSINO DE CIÊNCIAS}

A natureza das atividades práticas é ampla e engloba estratégias pedagógicas variadas, tais como: jogos didáticos, atividades experimentais em laboratórios, saídas de campo, modelos didáticos, júri simulado, entre outros. Portanto, atividades experimentais seriam, necessariamente, práticas. Segundo Krasilchik (2008), as principais funções das aulas práticas são: despertar e manter o interesse dos alunos; envolver os estudantes em investigações científicas; desenvolver a capacidade de resolver problemas; compreender conceitos básicos e desenvolver habilidades. No caso específico de atividades práticoexperimentais, Leiria e Mataruco (2015) destacam outro aspecto relevante para uma aprendizagem significativa no ensino de Física, mas que podemos extrapolar, de uma forma geral, para o ensino de Ciência:

\footnotetext{
Deve-se relevar ainda a utilização dessas atividades em relação à interação social entre os jovens durante o processo, o trabalho em grupo que pode ser desenvolvido e que pode ensinar aos indivíduos atitudes e comportamentos que devem ter perante a sociedade ao qual estão fazendo parte, tornandose assim, agentes participantes e ativos nas situações que podem ocorrer em sua comunidade (LERIA; MATARUCO, 2015, p. 32.225).
}

Ainda explorando as contribuições das atividades experimentais no ensino de Ciências, Oliveira (2010) destaca: o desenvolvimento da iniciativa pessoal e da tomada de decisão, o estímulo da criatividade, o aprimoramento da capacidade de observação e registro de informações, o aprendizado de análise de dados e da proposição de hipóteses para os fenômenos, a possibilidade de se detectar e corrigir erros conceituais dos alunos, a compreensão da natureza da ciência e do papel do cientista em uma investigação, a compreensão das relações entre Ciência, Tecnologia e Sociedade e o aprimoramento de habilidades manipulativas. A autora, assim como os demais supracitados, também aponta o aprendizado de conceitos científicos, a capacidade de trabalhar em grupo e a motivação e o despertar a atenção dos alunos que as atividades experimentais possibilitam em aulas de Ciências.

Ressaltamos também que as habilidades desenvolvidas em atividades prático-experimentais - que ocorrem, majoritariamente, em laboratórios didáticos - permitem que o estudante tenha contato e manipule instrumentos próprios deste ambiente (como microscópio e vidrarias) e que fazem parte da cultura científica. Logo, se consideramos que aprender ciências não é aprender só conteúdo, mas é também ser inserido nesse universo cultural da Ciência atribuímos outro valor às aulas práticas e experimentais de Ciências e Biologia. Nesse sentido, é fundamental a consideração feita por Selles $(2008$, p. 612) de que "a experimentação didática difere-se da científica sem apagar completamente os elementos identificadores do mundo científico, mas conservando traços do contexto de produção que são recontextualizados no ambiente escolar".

Já na década de 1970, Ferreira (1978, apud MALHEIRO, 2016) classificou as abordagens experimentais no ambiente do laboratório, identificando-as como: experiência de cátedra, laboratório tradicional (ou laboratório estruturado, de acordo com MOREIRA; GONÇALVEZ, 1980, ou "laboratório de fading", segundo PIMENTEL; SAAD, 1999), laboratório divergente (ou laboratório não estruturado, 
como denominado por MOREIRA; GONÇALVEZ, 1980), laboratório aberto, laboratório de projetos, laboratório a disposição do aluno e laboratório por redescoberta. Borges (2002) discorre sobre alguns objetivos implícitos que os professores e estudantes tradicionalmente associam aos laboratórios de Ciências, a saber: verificar/comprovar leis e teorias científicas; ensinar o método científico e apreciar a natureza da ciência; facilitar a aprendizagem e compreensão de conceitos; e ensinar/adquirir habilidades práticas e técnicas. No entanto, o autor sinaliza que alguns objetivos "derivam de concepções equivocadas acerca da natureza dos processos de aprendizagem e de produção de conhecimento cientificamente válido" (p. 310/311) e recomenda ao professor que realize atividades pré-laboratório que explicitem os objetivos pretendidos e as ideias iniciais dos estudantes, além de após a sua realização discutir com os alunos os resultados e as limitações.

Autores como Pinho Alves (2000), Gonçalves e Galiazzi (2004), Stuart e Marcondes (2007) e Selles (2008) referem-se, especificamente, às atividades experimentais. Pinho Alves (2000) utiliza o termo atividade experimental entendendo-a relacionada ao fenômeno didático, tendo como função a promoção do diálogo entre o professor (mediador), o aluno e o conhecimento científico por meio do diálogo construtivista. Para autores como Gonçalves e Galiazzi (2004) e Stuart e Marcondes (2007) as atividades experimentais devem ser investigativas incentivando a discussão, a elaboração de hipóteses (levantamento de questionamentos), a interpretação dos dados e a elaboração de conclusões em busca da resolução de problemas, a partir da discussão entre os conhecimentos prévios dos alunos e aqueles sistematizados pelas explicações científicas.

Somando-se à discussão supracitada, Araújo e Abib (2003), em uma pesquisa bibliográfica sobre o uso da experimentação no ensino de Física, analisaram vários elementos das produções localizadas, entre eles, o grau de direcionamento das atividades experimentais, classificando-as como sendo de demonstração/observação, verificação e investigação. De acordo com os autores, as atividades de demonstração ilustram "alguns aspectos dos fenômenos físicos abordados, tornando-os de alguma forma perceptíveis e com possibilidade de propiciar aos estudantes a elaboração de representações concretas referenciadas" (p. 181). Essas atividades podem, no entanto, ser desenvolvidas através de dois procedimentos metodológicos distintos, a saber: por demonstrações fechadas (por simples ilustrações de um determinado fenômeno físico, sendo uma atividade centrada no professor) ou por demonstrações abertas (apresentam flexibilidade para discussões que permitem o aprofundamento de aspectos conceituais e práticos e o levantamento de hipóteses que consistem em ponto de partida para explorar de forma mais profunda o tema). As atividades de verificação "são caracterizadas por uma maneira de se conduzir a atividade experimental na qual se busca a verificação da validade de alguma lei física, ou mesmo de seus limites de validade" (p. 183). Estas são "um recurso valioso para tornar o ensino estimulante e a aprendizagem significativa, promovendo uma maior participação dos alunos", para desenvolver a capacidade de se efetuar generalizações e para "tornar o ensino mais realista, no sentido de se evitar alguns erros conceituais observados em livros-texto" ( $p$. 183). Finalmente, as atividades experimentais de investigação apresentam uma maior flexibilidade metodológica por não se deterem a roteiros fechados 
buscando a resolução de problemas, o teste de hipóteses e o desenvolvimento da capacidade de observação e descrição de fenômenos que contribuem para o progresso intelectual dos estudantes. Os autores destacam as vantagens dessas atividades:

(...) o próprio caráter de investigação das mesmas pode ser considerado como um elemento facilitador para uma abordagem que seja centrada nos aspectos cognitivos do processo de ensino-aprendizagem, intrínsecos de uma metodologia que busca uma transformação mais profunda nos estudantes, seja ela vinculada aos aspectos conceituais, (...) ou mesmo comportamentais, como a capacidade de reflexão, abstração, generalização, síntese e de senso crítico (ARAÚJO; ABIB, 2003, p. 186).

No quadro 1 apresentamos uma síntese das principais contribuições das atividades práticas e/ou experimentais no ensino de Ciências partindo das considerações teóricas dos autores supracitados.

Quadro 1 - Contribuições das atividades prático-experimentais no ensino de Ciências

\begin{tabular}{|c|c|}
\hline $\begin{array}{l}\text { Atividades práticas e/ou } \\
\text { experimentais (Autores) }\end{array}$ & Contribuições \\
\hline $\begin{array}{l}\text { Atividades práticas } \\
\text { (Krasilchik, 2008) }\end{array}$ & $\begin{array}{l}\text { - } \text { despertam e mantêm o interesse dos alunos; } \\
\text { - } \text { cienvolvem os estudantes em investigações } \\
\text { - desenvolvem a capacidade de resolver problemas; } \\
\text { - compreendem conceitos básicos e desenvolvem } \\
\text { habilidades; }\end{array}$ \\
\hline $\begin{array}{l}\text { Atividades } \\
\text { experimentais/investigativas } \\
\text { (Gonçalves; Galiazzi, 2004; } \\
\text { Stuart; Marcondes, 2007) }\end{array}$ & $\begin{array}{l}\text { - incentivam a discussão e a elaboração de hipóteses } \\
\text { (levantamento de questionamentos); } \\
\text { - permitem a interpretação dos dados e a elaboração } \\
\text { de conclusões em busca da resolução de problemas; } \\
\text { - possibilitam a discussão entre os conhecimentos } \\
\text { prévios dos alunos e aqueles sistematizados pelas } \\
\text { explicações científicas; }\end{array}$ \\
\hline $\begin{array}{l}\text { Atividades experimentais } \\
\text { (Leiria; Mataruco, 2015) }\end{array}$ & $\begin{array}{l}\text { - permitem interação social entre os estudantes que } \\
\text { desenvolvem trabalho em grupo (atitudes e } \\
\text { comportamentos na sociedade; agentes } \\
\text { participantes e ativos em sua comunidade); }\end{array}$ \\
\hline $\begin{array}{l}\text { Atividades experimentais } \\
\text { (Oliveira, 2010) }\end{array}$ & $\begin{array}{l}\text { - desenvolvem a iniciativa pessoal e a tomada de } \\
\text { decisão; } \\
\text { - estimulam a criatividade; } \\
\text { - aprimoram a capacidade de observação e registro } \\
\text { de informações; } \\
\text { - permitem a análise de dados e a proposição de } \\
\text { hipóteses para os fenômenos; } \\
\text { - possibilitam detectar e corrigir erros conceituais dos } \\
\text { alunos; } \\
\text { - permitem compreender a natureza da ciência e do } \\
\text { papel do cientista em uma investigação; } \\
\text { - envolvem a compreensão das relações entre ciência, } \\
\text { tecnologia e sociedade; } \\
\text { - aprimoram habilidades manipulativas; }\end{array}$ \\
\hline
\end{tabular}




\begin{tabular}{|c|c|}
\hline $\begin{array}{l}\text { Atividades práticas e/ou } \\
\text { experimentais (Autores) }\end{array}$ & Contribuições \\
\hline $\begin{array}{l}\text { Atividades experimentais } \\
\text { (Araújo; Abib, 2003) }\end{array}$ & $\begin{array}{l}\text { - De demonstração/observação: ilustram fenômenos } \\
\text { naturais, tornando-os de alguma forma perceptíveis. } \\
\text { Podem ser demonstrações fechadas (atividade } \\
\text { centrada no professor) ou abertas (permitem o } \\
\text { aprofundamento de aspectos conceituais e práticos e } \\
\text { o levantamento de hipóteses); } \\
\text { - De verificação: buscam verificar a validade de } \\
\text { alguma lei física ou seus limites de validade; } \\
\text { - De investigação: não se detêm a roteiros fechados } \\
\text { buscando a resolução de problemas; }\end{array}$ \\
\hline
\end{tabular}

Fonte: Adaptado de Krasilchik (2008), Gonçalves e Galiazzi (2004), Stuart e Marcondes (2007), Leiria e Mataruco (2015), Oliveira (2010) e Araújo e Abib (2003).

No contexto deste trabalho consideramos que as atividades práticoexperimentais são aquelas que se caracterizam pela sua dinâmica e guardam semelhanças com relação à racionalidade científica e aos procedimentos de produção de conhecimentos em laboratórios de pesquisa. Entretanto, são atividades concebidas para situações de ensino visando à aprendizagem de competências e habilidades próprias das Ciências da Natureza (BRASIL, 2006). Focamos na elaboração e na execução dessas atividades em aulas de Ciências e Biologia em turmas do ensino fundamental e médio de uma escola pública estadual do estado do RJ parceira do Subprojeto Biologia PIBID-CAPES da Faculdade de Formação de Professores (FFP) da Universidade do Estado do Rio de Janeiro (UERJ). Licenciandos do curso de Ciências Biológicas foram os responsáveis pela elaboração das atividades prático-experimentais, tendo sido supervisionados pelas professoras regentes destas turmas e pela professora coordenadora do subprojeto. O objetivo deste trabalho consiste em avaliar as atividades prático-experimentais elaboradas e executadas pelos bolsistas de iniciação à docência buscando, ainda, identificar suas contribuições para o processo de ensino-aprendizagem em aulas de Ciências e Biologia e para a formação inicial dos futuros professores.

\section{CONTEXTO DE DESENVOLVIMENTO DAS ATIVIDADES: PIBID BIOLOGIA}

As atividades que são aqui relatadas situavam-se no âmbito do Programa Institucional de Bolsa de Iniciação à Docência (PIBID), mais especificamente, relacionado ao Subprojeto Biologia FFP-UERJ. O PIBID integra um grupo de ações coordenadas pela Diretoria de Formação de Professores da Educação Básica (DEB) que constituem a política nacional de formação de professores estabelecida pelo MEC em conjunto com a Coordenação de Aperfeiçoamento de Pessoal de Nível Superior (CAPES).

O PIBID foi criado em 2007 por meio do Edital MEC/CAPES/FNDE que trazia critérios de seleção pública com propostas de projetos de iniciação à docência. Esta primeira chamada definia os objetivos do PIBID, entre eles: incentivar a formação de professores para a educação básica, especialmente para o ensino médio; estimular a integração da educação superior com a educação básica no ensino fundamental e médio; e proporcionar aos futuros professores a 
participação em ações, experiências metodológicas e práticas docentes inovadoras, articuladas com a realidade local da escola'.

A estrutura do PIBID previa a organização em um grande projeto de uma instituição de ensino superior, o qual abrigaria subprojetos por áreas de conhecimento. Cada subprojeto era coordenado por professores universitários e deveria estabelecer parcerias com escolas públicas da educação básica. Estes eram responsáveis pela seleção dos professores supervisores que estavam em sala de aula e dos bolsistas de iniciação à docência (ID), estudantes de graduação matriculados em cursos de licenciatura plena. A escolha das escolas parceiras deveria ser justificada a partir de baixo desempenho no IDEB, tendo em vista que uma das contribuições do programa era a melhoria da qualidade do ensino e do desempenho dos estudantes da educação básica.

A UERJ iniciou sua participação no PIBID no Edital CAPES № 1/2011 e está presente até hoje no programa. O projeto institucional "Saber escolar e formação docente na Educação Básica" encontra-se vinculado à Coordenadoria de Avaliação, Projetos Especiais e Inovação (COPEI), instância da Sub-reitoria de Graduação (SR-1) da UERJ².

O Subprojeto Biologia da FFP teve início no primeiro ano de existência do projeto institucional, tendo a autora assumido sua coordenação a partir do edital de 2013, vigente entre os anos de 2014 a 2017. As equipes do subprojeto atuavam em escolas dos municípios de Niterói e São Gonçalo, RJ. Uma das escolas parceiras em 2017 era o Colégio Estadual Mário Tamborindeguy. Estivemos em duas equipes nessa escola (cada uma composta por cinco licenciandos), supervisionadas por duas professoras, em turmas de 7으, 8으 e 9으 anos do ensino fundamental e de 10 , 2 ㅇ e 3 o anos do ensino médio. Os dez bolsistas de ID cursavam Ciências Biológicas, se encontravam entre o 5ㅇ e o 8응 período da licenciatura e dedicavam-se 12 horas semanais ao subprojeto, sendo oito horas em sala de aula e quatro para planejamento das atividades. As equipes faziam reuniões de planejamento e de avaliação no início e ao final de cada bimestre.

O subprojeto Biologia FFP-UERJ centrou suas atividades em torno de 10 ações, sendo a ação de número quatro: elaboração de roteiros e realização de aulas experimentais no laboratório escolar de Ciências das escolas participantes, a partir da revitalização e ampliação de suas atuais atividades. O C. E. Mário Tamborindeguy possui um laboratório didático no qual era realizada a maior parte das aulas, inclusive teórico-expositivas. É importante ressaltar que essa escola atende a um público de estudantes carentes, moradores do bairro, e vem enfrentando um alto índice de evasão escolar e fechamento de turmas. As atividades desenvolvidas pelo subprojeto tinham, portanto, além do intuito de oferecer uma educação científica de qualidade aos envolvidos, o objetivo de tornar as aulas de Ciência e Biologia mais atrativas aos estudantes.

As atividades realizadas na escola foram classificadas em: atividades práticoexperimentais (as atividades realizadas no laboratório com auxílio de roteiros e manejo de vidrarias e equipamentos); materiais didáticos e midiáticos (cartazes, murais, maquetes e modelos didáticos); atividades lúdicas (paródias e jogos didáticos); aulas teórico-expositivas dialogadas; e debates (buscando estimular a curiosidade e o interesse dos alunos). Neste trabalho, descrevemos apenas as atividades prático-experimentais desenvolvidas ao longo do ano letivo de 2017. 
O planejamento das atividades era feito de acordo com a demanda da professora supervisora: no início do bimestre ela sinalizava os conteúdos que possibilitavam a realização de aulas no laboratório. Os licenciandos se subdividiam em duplas ou trios e elaboravam os roteiros das práticas; para tanto, eram consultados livros didáticos, sites da internet e anais de eventos científicos. Em seguida, decidiam quais práticas eram viáveis de execução e fechavam o planejamento do bimestre. Várias dessas discussões eram feitas via e-mail e grupo no WhatsApp por meio das quais era possível tomar decisões coletivas. Todas as aulas ocorreram no laboratório didático (exceto a atividade "Circuito dos sentidos" que aconteceu no refeitório) e foram utilizados equipamentos nele existentes e materiais de baixo custo os quais, na maioria das vezes, eram adquiridos e levados para a escola pelos próprios licenciandos.

\section{METODOLOGIA DE ANÁLISE DAS ATIVIDADES PRÁTICO-EXPERIMENTAIS}

A metodologia adotada na elaboração da pesquisa foi qualitativa e organizada a partir da técnica de triangulação de dados (MINAYO, 2010). As avaliações sobre as atividades foram feitas por meio de três instrumentos: avaliações das atividades, reflexões presentes em textos acadêmicos e questionário individual. As avaliações foram coletadas a partir do relatório coletivo anual confeccionado pelos licenciandos sob a supervisão das professoras regentes. Neste relatório, as atividades tinham seus objetivos apresentados, havia uma descrição, situando a série e o bimestre em que foi desenvolvida, e uma síntese dos resultados alcançados; neste campo os licenciandos realizavam uma pequena avaliação. No Quadro 2 apresentamos um fragmento do relatório anual (com uma atividade para fins de exemplificação) submetido à coordenação institucional do PIBID.

Quadro 2 - Fragmento do relatório anual de atividades de 2017 do Subprojeto Biologia FFP-UERJ

\begin{tabular}{|c|c|c|c|}
\hline $\begin{array}{l}\text { Indicador } \\
\text { da } \\
\text { atividade }\end{array}$ & $\begin{array}{l}\text { Objetivo da } \\
\text { atividade }\end{array}$ & $\begin{array}{l}\text { Descrição sucinta da } \\
\text { atividade (inserir início } \\
\text { e período de realização) }\end{array}$ & Resultados alcançados \\
\hline 2 & $\begin{array}{l}\text { Realização de } \\
\text { atividades } \\
\text { prático- } \\
\text { experimentais: } \\
\text { Misturas } \\
\text { homogêneas e } \\
\text { heterogêneas }\end{array}$ & $\begin{array}{l}\text { Objetivo: Compreender } \\
\text { a diferença entre } \\
\text { misturas homogêneas e } \\
\text { heterogêneas. } \\
\text { Descrição: No } \\
\text { laboratório de ciências a } \\
\text { turma foi dividida em } 4 \\
\text { grupos. Cada grupo } \\
\text { ficou responsável por } \\
\text { realizar experiências } \\
\text { previamente } \\
\text { selecionadas pelos } \\
\text { bolsistas para identificar } \\
\text { substâncias } \\
\text { heterogêneas e } \\
\text { homogêneas. } \\
\text { Turma 901/9ano EF. }\end{array}$ & $\begin{array}{l}\text { Os alunos da turma } 901 \\
\text { foram muito participativos } \\
\text { e interessados em } \\
\text { entender todo processo, } \\
\text { propondo entre eles } \\
\text { mesmos algumas } \\
\text { sugestões de misturas. } \\
\text { Nesta atividade, } \\
\text { percebemos claramente } \\
\text { que uma aprendizagem } \\
\text { que correlaciona os } \\
\text { aspectos que os alunos } \\
\text { vivenciam em seu } \\
\text { cotidiano tende a tornar- } \\
\text { se mais signficativa e } \\
\text { possui muito mais sentido } \\
\text { na construção e no }\end{array}$ \\
\hline
\end{tabular}




\begin{tabular}{|l|l|l|l|}
\hline $\begin{array}{l}\text { Indicador } \\
\text { da } \\
\text { atividade }\end{array}$ & $\begin{array}{l}\text { Objetivo da } \\
\text { atividade }\end{array}$ & $\begin{array}{l}\text { Descrição sucinta da } \\
\text { atividade (inserir início } \\
\text { e período de realização) }\end{array}$ & Resultados alcançados \\
\hline & & $\begin{array}{l}\text { Atividade realizada no } \\
\text { 2o bimestre. }\end{array}$ & $\begin{array}{l}\text { entendimento dos } \\
\text { conceitos científicos. }\end{array}$ \\
\hline
\end{tabular}

Fonte: Relatório anual do Subprojeto Biologia FFP-UERJ (2018).

O segundo instrumento de fonte de dados utilizado foram trabalhos (um resumo e um trabalho completo) apresentados em eventos científicos e autorados pelos bolsistas de iniciação à docência, pela professora supervisoras e pela coordenadora do subprojeto (RIBEIRO et al., 2017; SILVA et al., 2018). Nestes textos são relatadas duas atividades prático-experimentais (uma sobre Histologia e outra sobre Energia Mecânica) desenvolvidas na escola parceira e apresentadas avaliações dos bolsistas sobre essas atividades. Em ambos os casos foram produzidas reflexões sustentadas na literatura da área.

Por fim, o terceiro conjunto de dados foi proveniente de questionário individual enviado por e-mail (formulário Google) e respondido pelos antigos bolsistas de iniciação à docência após um ano e meio do encerramento das atividades do Subprojeto Biologia (em julho de 2019). O questionário tinha as seguintes questões:

1) Participei do Subprojeto Biologia PIBID FFP-UERJ nos anos:

\section{$\begin{array}{llll}\text { ( ) } 2014 & \text { ( ) } 2015 & \text { ( ) } 2016 & \text { ( ) } 2017\end{array}$}

2) Você considera que as atividades práticas-experimentais são mais importantes por que? (Marque apenas TRÊS opções)

( ) Aumentam o interesse do aluno pela Ciência e pelas aulas de Ciências.

( ) Permitem que o aluno entenda melhor as etapas do método científico.

( ) Fazem com que o aluno compreenda a lógica do raciocínio científico.

( ) Permitem que o aluno reconheça que a atividade científica pode ser desenvolvida por qualquer pessoa.

( ) Propiciam a interação entre alunos e entre professor-aluno.

( ) Estimulam o desenvolvimento de habilidades cognitivas próprias relacionadas à Ciência.

( ) Preparam o aluno para um posicionamento político futuro com relação aos assuntos científicos na sociedade.

3) Quais os conteúdos que você mais se dedicou na elaboração de atividades prático-experimentais?

( ) Citologia/Genética ( ) Física/Química ( ) Fisiologia/Anatomia

( ) Ecologia/Zoologia/Botânica Outro:

4) Cite pelo menos DUAS principais dificuldades encontradas na realização de atividades práticas-experimentais.

5) Qual aula prática-experimental mais te marcou? Conte um pouco sobre ela, o que achou do seu planejamento e execução. 
6) Como você considera que sua participação no PIBID, especificamente na elaboração de aulas práticas-experimentais, ajudou na sua formação de professor de Ciências?

A partir da reunião dos dados obtidos por meio dessas três fontes percebemos como os licenciandos avaliaram as contribuições do envolvimento em atividades prático-experimentais durante seu processo de formação inicial e, posteriormente, após sua graduação tendo em vista que alguns deles já atuam no magistério da educação básica. Os resultados foram analisados de forma interpretativa pautada na literatura.

\section{DESCRIÇÃO DAS ATIVIDADES PRÁTICO-EXPERIMENTAIS}

As atividades prático-experimentais foram planejadas e executadas em equipes, conforme descrito anteriormente. As 15 atividades práticoexperimentais desenvolvidas pelas duas equipes no C. E. Mário Tamborindeguy, no ano de 2017, aconteceram em turmas do 7ㅇ, 8ㅇ e 9o anos do ensino fundamental e do 1ㅇ e 2o anos do ensino médio. Os conteúdos curriculares contemplados nessas aulas são considerados pelos documentos oficiais (Currículo Mínimo do Estado do Rio de Janeiro e Parâmetros Curriculares Nacionais) como sendo centrais em aulas de Ciências e Biologia.

A seguir são enumeradas cada uma das atividades prático-experimentais, com uma descrição do ano e do bimestre em que foram realizadas e seus objetivos.

a) Energia Mecânica (9o ano do EF - 1으 bimestre) - objetivos: visualizar os conceitos de energia cinética e energia potencial a partir de objetos do cotidiano do aluno; entender os conceitos físicos associados a energia do movimento;

b) Misturas (9 ano do EF - 2o bimestre) - objetivo: compreender a diferença entre misturas homogêneas e heterogêneas (conteúdos de Química);

c) Digestão (2 ano do EM - 2으 bimestre) - objetivo: reconhecer os processos físico-químicos relacionados à digestão de forma simples por meio de cinco experiências. O roteiro desta aula prática encontra-se publicado em Matos e Galieta (2019);

d) Fermentação e fotossíntese (9o ano do EF - 2o bimestre) - objetivos: demonstrar a ocorrência de fotossíntese e fermentação, relacionando-os como processos energéticos; ilustrar como acontecem os processos de fermentação e fotossíntese para além da teoria, observando-as na prática. Os roteiros dessas atividades estão publicados em Bianchini e Galieta (2019);

e) Extração de DNA (1ㅇa ano do EM - 2ㅇ bimestre) - objetivos: identificar os princípios básicos da extração de material genético e realizá-los de maneira simples; explicar como é a estrutura e composição química das moléculas de DNA;

f) Fermentação e cromatografia ( $2 \circ$ ano do EM - 2ㅇ bimestre) objetivo: compreender o processo de fermentação; visualizar alguns dos diferentes tipos de pigmentos que podem ser encontrados na natureza; 
g) Fermentação (9o ano do EF - 2ㅇ bimestre) - objetivo: compreender a importância do processo de fermentacão e como ele ocorre;

h) Propriedades da matéria ( 9 o ano do $\mathrm{EF}-20$ bimestre) - objetivo: compreender e relembrar as propriedades da matéria (massa, volume, impenetrabilidade, compressibilidade, elasticidade e densidade);

i) Construção de terrários em garrafas pet (7ํano do EF - 2ำ bimestre) - objetivo: simular e demonstrar condições e características de um ecossitema, bem como o desenvolvimento das plantas;

j) Substâncias e misturas (9o ano do EF - 2o bimestre) - objetivo: proporcionar aos alunos uma melhor compreensão sobre substâncias simples e compostas e misturas homogêneas e heterogêneas;

k) Propriedades da Matéria (9o ano do EF - 3o bimestre) - objetivo: compreender as propriedades da matéria;

I) Funções químicas: ácidos e bases (9o ano do EF - 3ㅇ bimestre) objetivos: identificar as principais características de uma reação química; revisar os conceitos de ácido e base através a observação do uso de indicadores de acidez;

m) Circuito dos sentidos (8 ano do EF - 3 bimestre) - objetivo: perceber os cinco sentidos em situações cotidianas, bem como relacioná-los dentro de uma visão integrada com o corpo humano;

n) Prática sobre $\mathrm{pH}$ (9ㅇ ano do EF - 3 bimestre) - objetivos: compreender o que é potencial hidrogeniônico; diferenciar $\mathrm{pH}$ ácido, neutro e básico com um indicador natural;

o) Modelo atômico: prática com luz negra (9o ano do EF - 4으 bimestre) - objetivo: identificar e compreender o modelo atômico e seus componentes, bem como a diferença entre florescência e fosforescência;

Podemos observar pela descrição acima que as atividades abordaram conteúdos curriculares de Biologia, Física e Química. Isso ocorreu devido à existência de turmas de 9 o ano do ensino fundamental, as quais desafiaram enormemente os licenciandos no planejamento de aulas práticas experimentais sobre conceitos tradicionais e fenômenos físico-químicos. Os documentos curriculares oficiais preveem para esta série um conjunto de conhecimentos da Física e da Química que serviriam como uma introdução a essas disciplinas no ensino médio (SEEDUC-RJ, 2012). No entanto, são os professores graduados em Ciências Biológicas que geralmente assumem as turmas de 9 ano de modo que o desenvolvimento de atividades prático-experimentais sobre esses conteúdos que, muitas das vezes, não estão presentes em disciplinas da licenciatura em Biologia, foi fundamental para o aprimoramento dos futuros professores.

Percebemos, ainda, a prevalência de atividades no segundo e terceiro bimestres. Tal fato se deu porque no primeiro bimestre os licenciandos realizavam ações relacionadas à observação da dinâmica escolar, reconhecendo as turmas e as necessidades dos estudantes, e no quarto bimestre tinham que dar conta - junto às professoras regentes supervisoras - de conteúdos que ficaram defasados ao longo do ano letivo.

Os licenciandos utilizaram nas atividades de estratégias de leitura e de escrita, a partir de roteiros pré-elaborados, anotações no quadro e nos cadernos e respostas a exercícios. Desta forma, as aulas prático-experimentais serviram 
não apenas para a compreensão de aspectos da produção do conhecimento científico e de determinados conceitos, como também foram importantes para que os bolsistas explorassem diversas possibilidades metodológicas.

\title{
AVALIAÇÃO DAS ATIVIDADES PRÁTICO-EXPERIMENTAIS PELOS EX-BOLSISTAS DE INICIAÇÃO À DOCÊNCIA
}

As contribuições das atividades prático-experimentais para o processo de ensino-aprendizagem e para a formação dos licenciandos foram identificadas por meio de três instrumentos de curto e longo prazo: as avaliações (presentes no relatório coletivo produzido ao final do ano letivo e submetido a CAPES pela coordenação institucional do PIBID-UERJ); as reflexões presentes em textos acadêmicos (apresentados em eventos científicos); e as respostas ao questionário estruturado.

As avaliações dos licenciandos presentes no campo "Resultados alcançados" do relatório anual destacam: a participação dos estudantes, a didatização de conceitos científicos abstratos, a relação entre teoria e prática, a presença de situações cotidianas nas experiências, os acertos e erros nos experimentos, o aspecto lúdico e a manipulação de equipamentos. Algumas delas são destacadas abaixo:

\begin{abstract}
"Os alunos foram bastante participativos nas atividades propostas, ao final puderam visualizar concretamente a conversão das energias mecânicas em objetos do dia a dia, trazendo os conceitos abstratos da física para um plano mais realista."
\end{abstract}

\begin{abstract}
"Nesta atividade percebemos claramente que uma aprendizagem que correlaciona os aspectos que os alunos vivenciam em seu cotidiano tende a tornar-se mais signficativa e possui muito mais sentido na construção e no entendimento dos conceitos científicos."

“(...) Terminado os experimentos de Fermentação pudemos constatar que os alunos esclareceram a maioria, senão todas, as suas dúvidas relacionadas ao processo de fermentação e perceberam que é um processo natural que ocorre em seu cotidiano. Já a prática de Fotossíntese não foi bem sucedida uma vez que os alunos não puderam observar diferenças entre os recipientes escuro/claro."
\end{abstract}

\footnotetext{
"Assim, eles conseguiram se aproximar da ciência, vendo de maneira prática o que estudaram em teoria. (...)."

"Os dois experimentos foram bastante divertidos e proveitosos para alunos, estagiários e professora, pois houve grande interesse e participação. Todos puderam manusear os equipamentos e ao final pode-se esclarecer diversas dúvidas (...)."
}

A partir das avaliações dos bolsistas de ID podemos notar várias das contribuições elencadas por Oliveira (2010) com relação às aulas práticas e experimentais. Por outro lado, não foi mencionado o papel das atividades na análise de dados e na proposição de hipóteses tendo em vista que elas foram essencialmente de demonstração/observação ou de verificação (ARAÚJO; ABIB, 2003). Além disso, no quarto excerto destacado encontramos um problema na 
ideia de "prática como aplicação da teoria", algo que Giani (2010) discute apoiado em Axt (1991):

Nesse caso, o papel reservado para a experimentação é o de verificar aquilo que é informado na aula teórica, contribuindo para uma visão totalmente distorcida da relação entre teoria e prática. Na realidade, não deveria haver distinção entre sala de aula e laboratório, uma vez que, diante de um problema, o estudante deve fazer mais do que simples observações e medidas experimentais, pois as possíveis hipóteses por eles criadas, na tentativa de solucionar o problema, deveriam ser discutidas com o objetivo de se avaliar a pertinência, a viabilidade e, se for o caso, propor procedimentos que possam verificar as diferentes propostas de solução (GIANI, 2010, p. 19).

As atividades prático-experimentais também foram objetos de textos acadêmicos produzidos pelos licenciandos em coautoria com as professoras supervisoras e coordenadora do subprojeto, a partir da literatura da área de Educação em Ciências sobre experimentação. Nesses textos, os licenciandos relatam atividades específicas e fazem avaliações sobre elas. No trabalho "Conceitos de energia mecânica no ensino fundamental: relato da atividade prática "Carrinho de ratoeira'" (RIBEIRO et al., 2017), os bolsistas de ID apresentam uma aula sobre energia mecânica em uma turma de 9 o ano do ensino fundamental e suas avaliações realizadas a partir das respostas a um exercício realizado após a prática. Eles comentam:

(...) pudemos perceber que os alunos da turma 901 tiveram dificuldade de interpretação e de resolução das questões da atividade prática 'Carrinho de Ratoeira'. Esse fato pode ter se dado por vários motivos, dentre eles a ambiguidade nas palavras e conceitos utilizados para a exposição do conteúdo. A partir das análises dos estudos dirigidos e das dúvidas que surgiram durante as aulas notamos que a maior dificuldade dos alunos está em desassociar o conceito de energia utilizado do domínio científico do conceito de energia presente no cotidiano (RIBEIRO et al., 2017, p. 1).

Nesta reflexão, os licenciandos apontam para outro aspecto relevante em aulas de Ciências que é o papel da linguagem na apropriação de conceitos científicos (MORTIMER, 1998), ressaltando as dificuldades apresentadas pelos estudantes na aprendizagem formal dos processos relacionados à energia mecânica por conta, inclusive, do uso de palavras que estão presentes em seu cotidiano.

No trabalho "Relato de uma atividade teórico-prática sobre histologia no ensino médio realizada no âmbito do PIBID" (SILVA et al., 2018) os bolsistas de ID descrevem uma aula teórica com auxílio de apresentação de slides, seguida por aula prática dada no laboratório da escola. As avaliações dos licenciandos giram em torno da relação teoria e prática nas aulas de Biologia.

Com esta atividade vimos que a aula prática não tem como função complementar a aula teórica porque ela também serve como um espaço para a compreensão de conceitos. Além disso, a atividade prática também propicia a inserção do aluno em um ambiente científico, no qual ele pode manusear e entender o funcionamento de equipamentos laboratoriais (SILVA et al., 2018, p. 3017).

Aqui, em oposto ao que identificamos no relatório anual, notamos que os futuros professores compreendiam que a dicotomia entre teoria e prática poderia vir a se estabelecer como um equívoco nas atividades experimentais. Ou 
seja, identificam que a experimentação não é um espaço de verificação daquilo que foi informado na aula teórica, algo que poderia contribuir para a construção de uma visão totalmente distorcida da relação entre teoria e prática (AXT, 1991).

Além disso, eles incluíram reflexões sobre o material de apoio utilizado nas aulas e a elaboração de questões em exercícios que, de fato, propiciem o aprendizado e não somente a memorização.

Observamos também que temas discutidos durante a aula prática, e que não constavam no texto de apoio, sinalizavam nas respostas dos questionários dificuldades de assimilação de determinado conceito. Por exemplo, na questão que abordava a relação da densidade óssea e a osteoporose pudemos localizar problemas na compreensão do conceito de densidade. Isso destaca a importância de elaboração de perguntas que exijam reflexão dos alunos, pois, caso contrário, eles somente reproduzirão cópias do texto de apoio ou livros didáticos (SILVA et al., 2018, p. 3018).

Finalmente, tendo em vista a necessidade de uma avaliação de longo prazo sobre as atividades prático-experimentais, foi elaborado um questionário que foi respondido por cinco dos dez bolsistas de iniciação à docência atuantes em 2017. Três deles fizeram parte da equipe desde 2015, um desde 2016 e outro somente integrou a equipe no último ano (esses dados foram retirados da primeira pergunta).

A segunda questão buscava identificar quais as compreensões sobre a importância da experimentação. Em resposta à pergunta "Você considera que as atividades práticas-experimentais são mais importantes por quê? (Marque apenas três opções)", as opções mais marcadas foram: em primeiro "Fazem com que o aluno compreenda a lógica do raciocínio científico" e "Aumentam o interesse do aluno pela Ciência e pelas aulas de Ciências" (cada uma assinalada quatro vezes); seguida por "Permitem que o aluno entenda melhor as etapas do método científico" e "Permitem que o aluno reconheça que a atividade científica pode ser desenvolvida por qualquer pessoa" (cada uma assinalada três vezes). A opção "Estimulam o desenvolvimento de habilidades cognitivas próprias relacionadas à Ciência" ficou em terceiro, tendo sido marcada duas vezes. Notamos, portanto, que os futuros professores reconhecem a importância das atividades prático-experimentais para a compreensão de aspectos da natureza da Ciência (BORGES, 2002; OLIVEIRA, 2010). Além disso, dão ênfase à finalidade dessas atividades na motivação e no interesse dos estudantes (KRASILCHIK, 2008; PRADO; WESENDONK, 2019).

As respostas à terceira questão corroboram o que foi apresentado na seção anterior. A pergunta era: "Quais os conteúdos que você mais se dedicou na elaboração de atividades prático-experimentais?". A alternativa sinalizada com maior frequência foi "Física e Química" (50\%). Este é um dado particularmente interessante, pois sinaliza o protagonismo da experimentação em aulas de Física e Química. No caso específico do ensino de Física, Leiria e Mataruco (2015) argumentam que o uso dessas atividades vai além "da questão de somente ser realizada para a comprovação de conceitos e teorias abordadas em sala ou de serem desenvolvidas com a intenção de motivar os indivíduos, procurando entusiasmá-los com a disciplina" (p. 32.224). Os autores também destacam a importância da experimentação para o deslocamento de conceitos científicos de um mundo abstrato para sua interação com o mundo científico. 
A quarta questão: "Cite pelo menos duas principais dificuldades encontradas na realização de atividades práticas-experimentais.", revelou que o principal problema identificado pelos ex-bolsistas foi a falta/escassez de materiais para a realização das atividades. Esse dado corrobora algo discutido por Santos (2001) ao constatar que a maior parte das pesquisas sobre experimentação utilizam materiais de baixo custo. Outros aspectos ressaltados foram: não cooperação dos alunos e a falta de tempo para desenvolver de forma mais abrangente as práticas. O Subprojeto Biologia FFP-UERJ contou com verba para aquisição de materiais somente em seus dois primeiros anos (2014 e 2015). Nos outros dois anos, os próprios bolsistas de ID e as professoras supervisoras adquiriam e levavam os materiais necessários para a realização das aulas práticas. Isso demonstra o alto grau de comprometimento desses futuros professores que, por vezes, sentiam-se frustrados quando os estudantes não colaboravam com as atividades. Entre as limitações do PIBID, sinalizadas na revisão de Ferraz et al. (2017) sobre a produção acadêmica na área de Biologia, "destacam-se questões relativas às próprias condições de trabalho dos professores nas escolas e à falta de infraestrutura das mesmas" (p. 303). Desta forma, percebemos que os entraves encontrados por essa equipe têm sido vivenciados em outros subprojetos do programa.

Algumas respostas à quinta questão: "Qual aula prática-experimental mais te marcou? Conte um pouco sobre ela, seu planejamento e execução." foram:

\footnotetext{
"A aula prática sobre $\mathrm{pH}$, onde os alunos puderam reconhecer os valores de pH das substâncias do dia-a-dia, como sabão em pó, limão, e vinagre, que foram levados pelas bolsistas e pela professora, assim aprendendo o conceito de $\mathrm{pH}$ ácido, neutro e básico. (...) Nessa aula, os alunos ficaram muito entusiasmados quando as cores mudavam nos frascos, indicando o $\mathrm{pH}$ do produto utilizado, que era misturado com o suco de repolho roxo. Parecia que estávamos fazendo mágica, eles ficaram muito curiosos pra saber o porquê disso acontecer, foram muito participativos, todos queriam ver e entender e faziam perguntas, as quais nós bolsistas íamos respondendo."
}

"Aula prática sobre energia cinética e suas transformações onde usei 3 experimentos diferentes: pêndulo, carrinho de ratoeira e espiral de caderno pra mostrar como as energias são transmutáveis. Os experimentos requereram um tempo de planejamento grande por conta dos materiais que precisavam ser revistos e testados para que na aula não ocorressem contratempos, o que é um erro comum de se acreditar que não vá ocorrer. Os experimentos foram realizados numa aula específica só para atividades práticas uma semana após a aula com o conteúdo teórico abordado, servindo não somente como aproximação do teórico ao cotidiano do estudante, mas também como uma revisão da matéria já ensinada."

Nas respostas acima os ex-bolsistas de ID destacam, novamente, o entusiasmo e a curiosidade despertados pelas atividades, além da participação dos estudantes. Neste caso, a atividade realizada era do tipo de verificação (ARAÚJO; ABIB, 2003) e parece ter contribuído para a aprendizagem do conceito científico. A relação teoria e prática aparece na segunda resposta em que a aula no laboratório é dada posteriormente à teórica como uma revisão. Além disso, o ex-bolsista destacou a importância do planejamento prévio e o papel do erro na experimentação didática. 
Por fim, destaco três respostas à sexta pergunta: "Como você considera que sua participação no PIBID, especificamente na elaboração de aulas práticasexperimentais, ajudou na sua formação de professor de Ciências?":

\begin{abstract}
“Preparar aulas com a metodologia prática-experimental exige um esforço que vai além de apenas fazer que os alunos sigam um roteiro, mas sim de elaborar uma atividade que leve os alunos a participarem ativamente do processo, interagindo, levantando hipóteses, testando essas hipóteses até chegarem a uma conclusão e, de tal forma, poderá até mesmo ser feita associação com a construção epistemológica da ciência. Tal esforço, com certeza, contribuiu na minha formação docente."
\end{abstract}

\footnotetext{
"Através das aulas práticas-experimentais foi possível lidar com os erros e acertos, pois nem sempre as práticas davam certo e com isso foi possível nos preparar para lidar futuramente com essas situações nas aulas de Ciências e tirar proveito do porquê a prática ter dado errado, explicar e refletir isso com aluno. (...)"

\begin{abstract}
"Hoje como professora de Ciências e Biologia tenho mais segurança em propor atividades práticas as turmas devido as experiências do PIBID que me proporcionaram ampla bagagem onde posso por em prática atividades que eu mesma realizei durante o estágio."
\end{abstract}

Na primeira resposta, revela-se uma compreensão de aula práticaexperimental próxima de investigação a partir da participação ativa e da elaboração e teste de hipóteses pelos estudantes, algo que se aproximaria da produção do conhecimento científico (ARAÚJO; ABIB, 2003; STUART; MARCONDES, 2007). Nas outras duas, as ex-bolsistas enfatizam as vivências no PIBID que Ihes garantiram um aprendizado que lhes dá segurança para realizarem atividades dessa natureza em suas aulas.

\title{
CONSIDERAÇÕES FINAIS
}

As avaliações feitas pelos licenciandos que estiveram envolvidos no Subprojeto Biologia FFP-UERJ a curto e a longo prazo, indicam que a participação dos mesmos na elaboração e na execução de atividades prático-experimentais contribuiu para a formação docente e para a reflexão acerca da natureza da experimentação no ensino de Ciências e Biologia. Eles demonstram ter desenvolvido um olhar atento sobre a experimentação, considerando os diversos fatores que influenciam essas atividades. O processo de planejamento, e posterior avaliação, das aulas produzidas para o laboratório didático, sinaliza que o envolvimento em aulas práticas e experimentais foi fundamental para o aprendizado de estratégias didáticas.

Com relação às contribuições das atividades prático-experimentais para o ensino de Ciências, os ex-bolsistas de ID identificaram boa parte dos aspectos elencados por autores da área (sintetizados no Quadro 2) relacionados:

- ao interesse, a motivação dos estudantes;

- com a compreensão de conceitos científicos;

- por meio da discussão de conhecimentos prévios dos estudantes;

- através da interação social entre os estudantes em trabalhos em grupos; 
- em concordância a identificação das dificuldades de aprendizado dos estudantes;

- de acordo com a compreensão da natureza da ciência;

- em razão do aprimoramento de habilidades de manipulação instrumental de laboratório.

Além disso, utilizando a classificação de Araújo e Abib (2003), observamos que a maior parte das atividades prático-experimentais foi de demonstração fechada (totalmente conduzidas pelos bolsistas) e outras de verificação que eram executadas pelos próprios estudantes. Notamos também que atividades experimentais investigativas, segundo Stuart e Marcondes (2007), não estiveram presentes. Isso revela um aspecto importante dessas atividades: apesar de toda a discussão prévia no planejamento das atividades, ainda assim os experimentos pré-concebidos pelos licenciandos pouco abordaram a elaboração e o teste de hipóteses pelos estudantes.

Por outro lado, consideramos que as aulas realizadas no laboratório didático foram fundamentais para a formação dos futuros professores já que os objetivos implícitos no uso do laboratório estiveram presentes nas avaliações dos exbolsistas de ID, ainda que em algumas ocasiões não tivessem sido realizadas discussões prévias e posteriores às atividades em sala de aula (conforme sinalizado por BORGES, 2002). No entanto, é importante destacar que a escola parceira faz parte dos $38,8 \%$ das escolas públicas brasileiras de ensino médio que possuem laboratórios didáticos (INEP, 2019 - Censo Escolar de 2018). Desta forma, o PIBID ofereceu a oportunidade dos licenciandos/bolsistas estarem presentes em uma escola que dispõe desse espaço físico em sua infraestrutura, algo fundamental para o aprendizado de metodologias relacionadas à experimentação.

Finalmente, as avaliações demonstram o compromisso dos bolsistas de ID no planejamento, desenvolvimento e avaliação das atividades práticoexperimentais. Ferraz et al. (2017) apresentam as potencialidades do PIBID na formação de professores de Biologia, as quais estão relacionadas a diversos fatores. Entre eles, destacamos os que emergem das falas dos licenciandos: a formação de professores mais críticos e reflexivos sobre sua prática individual e coletiva; a melhoria dos aspectos pedagógicos e metodológicos da ação docente; e o questionamento sobre suas visões de senso comum sobre a ciência e a atividade científica. Logo, a vivência no programa, especificamente no envolvimento com a experimentação, proporcionou um ambiente de ação e reflexão, que provavelmente teria sido mais bem aproveitado caso houvesse acontecido um número maior de momentos de leituras teóricas sobre o tema, destinados aos futuros professores de Ciências e Biologia. 


\title{
Contributions of practical and experimental activities for teacher education: reflections from a project of initiation to teaching in biology
}

\begin{abstract}
The experimentation in science education is a distinctive feature of other areas. Practicalexperimental activities are used in science classes so that students of basic education understand aspects of the nature of science, exercise logical reasoning and develop cognitive skills related to scientific knowledge. In this work we evaluate the contributions of the practical-experimental activities elaborated and executed by graduates in Biological Sciences for the teaching-learning process in the practice of teaching and to the initial formation of the future teachers. The investigated scenario was a program of teaching initiation in a Biology Subproject whose actions were developed in a state college of Rio de Janeiro with the participation of ten fellows in 2017. The evaluations of the activities were made through three instruments: evaluations of activities (present in the annual collective report), reflections present in academic texts (presented at scientific events) and structured questionnaire (answered by the fellows after one and a half years after the end of the activities). Fifteen activities were elaborated, most of them demonstration and verification. It was concluded that, although they did not contemplate investigative actions, they were essential for the reflection on the role of experimentation in science teaching and in the initial formation of future science and biology teachers.
\end{abstract}

KEYWORDS: Pratical-experimental activities. Teacher training. Science and Biology teaching. 


\section{AGRADECIMENTOS}

Agradeço aos bolsistas de iniciação à docência que gentilmente responderam ao questionário e a toda equipe do Subprojeto Biologia FFP-UERJ pela parceria ao longo dos quatro anos em que trabalhamos juntos.

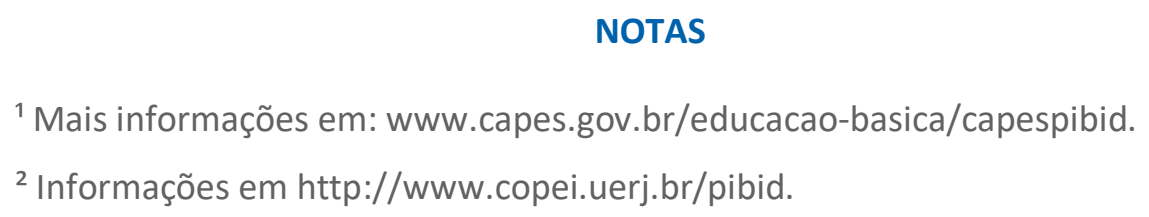

\section{REFERÊNCIAS}

ARAÚJO, M. S. T. de; ABIB, M. L. V. dos S. Atividades Experimentais no Ensino de Física: Diferentes Enfoques, Diferentes Finalidades. Revista Brasileira de Ensino de Física, v. 25, n. 2, p. 176-194, 2003.

ARRUDA, S. de M.; LABURÚ, C. E. Considerações sobre a Função do Experimento no Ensino de Ciências. In: NARDI, R. (Org.). Questões Atuais no Ensino de Ciências. São Paulo: Escrituras, 2005.

AULER, D.; DELIZOICOV, D. Alfabetização científico-tecnológica: para quê? Ensaio - Pesquisa em Educação em Ciências, v. 3, n. 1, p. 1-13, 2001.

AXT, R. O papel da experimentação no ensino de Ciências. In: MOREIRA, M. A.; AXT, R. (Orgs.). Tópicos em ensino de Ciências. Porto Alegre: Sagra: 1991.

BARRA, V. M.; LORENZ, M. K. Produção de materiais didáticos de ciências no Brasil, período: 1950 a 1980. Ciência e Cultura, Campinas, v. 38, n. 12, p. 19701983, 1986.

BIANCHINI, F. R. J.; GALIETA, T. Fotossíntese, respiração celular e fermentação. In: FREITAS, S. R. S.; SOUZA, L. L. de. (Orgs.). Ciência e Biologia: experimentos para a sala de aula. Manaus (AM): Editora UEA, 2019. p. 105-115.

BORGES, A. T. Novos rumos para o laboratório escolar de ciências. Caderno Brasileiro de Ensino de Física, v. 19, n. 3, p. 291-313, 2002.

BRASIL. Ministério da Educação, Secretária de Educação Básica. Orientações Curriculares para o Ensino Médio: Ciências da natureza, matemática e suas tecnologias. Brasília: MEC/SEB, v.2, 2006.

CUNHA, A. M. de O.; KRASILCHIK, M. A Formação Continuada de Professores de Ciências: percepções a partir de uma experiência. In: XIII Reunião Anual da Anped. Caxambú, 2000.

FERRAZ, D. F.; SANTOS, F. S. dos; FRANCISCO, A. C. de; CARLETTO, M. R. A produção científica com o tema PIBID na área de Ensino de Biologia. Ensino \& 
GIANI, K. A experimentação no Ensino de Ciências: possibilidades e limites na busca de uma Aprendizagem Significativa. Dissertação (Mestrado em Ensino de Ciências). Brasília: UnB, 2010.

GONÇALVES, F. P.; GALIAZZI, M. do C. A natureza das atividades experimentais no ensino de Ciências. In: MORAES, R.; MANCUSO, R. (Orgs.). Educação em Ciências: Produção de Currículos e Formação de Professores. Ijuí: Ed. Unijuí, 2004.

HODSON, D. Experimentos na ciência e no ensino de ciências. Educational Philosophy and Theory, 20, p. 53-66, 1988.

INEP. DADOS DO CENSO ESCOLAR - Noventa e cinco por cento das escolas de ensino médio têm acesso à internet, mas apenas $44 \%$ têm laboratório de ciências. Publicado em: 12 fev. 2019. Disponível em:

http://portal.inep.gov.br/artigo/-

/asset_publisher/B4AQV9zFY7Bv/content/dados-do-censo-escolar-noventa-ecinco-por-cento-das-escolas-de-ensino-medio-tem-acesso-a-internet-masapenas-44-tem-laboratorio-de-ciencias/21206. Acesso em: 05 abr. 2020.

KRASILCHIK, M. Prática de ensino de Biologia. São Paulo: Edusp, 2008.

LEIRIA, T. F.; MATARUCO, S. M. C. O papel das atividades experimentais no processo ensino-aprendizagem de Física. XII EDUCERE - Congresso Nacional de Educação. Curitiba: PUC-PR, 2015.

MALHEIRO, J. M. da S. Atividades experimentais no ensino de ciências: limites e possibilidades. ACTIO: Docência em Ciências, Curitiba, v. 1, n. 1, p. 108-127, 2016.

MATOS, P. N.; GALIETA, T. O que acontece com o alimento? A digestão na prática In: FREITAS, S. R. S.; SOUZA, L. L. de. (Orgs.). Ciência e Biologia: experimentos para a sala de aula. Manaus (AM): Editora UEA, 2019. p. 24-38.

MINAYO, M. C. S. Introdução. In: MINAYO, M. C. S.; ASSIS, S. G.; SOUZA, E. R. (Org.). Avaliação por triangulação de métodos: Abordagem de Programas Sociais. Rio de Janeiro: Fiocruz, 2010. p. 19-51.

MOREIRA, M. A.; GONÇALVES, E. S. Laboratório Estruturado versus Não Estruturado: um estudo comparativo em um curso individualizado. Revista Brasileira de Física, v. 10, n. 2, p. 389-404,1980.

MORTIMER, E. F. Sobre chamas e cristais: a linguagem cotidiana, a linguagem científica e o ensino de ciências. In: CHASSOT, A.; OLIVEIRA, R. J. (Orgs.). Ciência, ética e cultura na educação. São Leopoldo: Ed. Unisinos, 1998. p. 99-118.

MUNFORD, D.; LIMA, M. E. C. C. Ensinar ciências por investigação: em que estamos de acordo? Ensaio - Pesquisa em Educação em Ciências, v. 9, n. 1, p. 72 89, 2007. 
OLIVEIRA, J. R. S. de. Contribuições e abordagens das atividades experimentais no ensino de ciências: reunindo elementos para a prática docente. Acta Scientiae, v. 12, n.1, p.139-153, jan./jun. 2010.

PIMENTEL, C.; SAAD, F. D. Um Laboratório de Física Básica para os alunos de engenharia. In: Atas... IV Simpósio Nacional de Ensino de Física. Rio de Janeiro: SBF, 1999.

PINHO ALVES, J. Atividades experimentais: do método à prática construtivista. Tese (Doutorado em Educação). Florianópolis: UFSC/CED, 2000.

PINTO, S. P.; VIANNA, D. M. A ação-reflexão-ação na formação continuada de professores. Enseñanza de las Ciencias, núm. extra, p. 1-6, 2005.

PRADO, L. do; WESENDONK, F. S. Objetivos de utilização da experimentação presentes em produções acadêmicocientíficas publicadas nos anais de um evento da área de ensino de ciências. ACTIO: Docência em Ciências, v. 4, n. 2, p. 148$168,2019$.

RIBEIRO, T. C. S.; SILVA, M. C. F.; MATOS, P. N.; GALIETA, T. Conceitos de energia mecânica no ensino fundamental: relato da atividade prática "Carrinho de Ratoeira". In: Caderno de Resumos... II SEMINÁRIO REGIONAL PIBID - SE/I SEMINÁRIO ESTADUAL PIBID - RJ. Rio de Janeiro: PIBID Regional SE, 2017.

ROSITO, B. A. O ensino de ciências e a experimentação. In: MORAES, R. (Org.) Construtivismo e ensino de ciências: reflexões epistemológicas e metodológicas. 3. ed. Porto Alegre: EDIPUCRS, 2008, p. 195-208.

SANTOS, E. D. A Experimentação no Ensino de Ciências de 5a a 8a Séries do Ensino Fundamental: tendências da pesquisa acadêmica entre 1972-1995. Dissertação (Mestrado em Educação). Universidade Estadual de Campinas, 2001.

SEEDUC-RJ. Secretaria de Estado de Educação. Governo do Estado do Rio de Janeiro. Currículo Mínimo: Ciências e Biologia. RJ: SEEDUC, 2012.

SELLES, S. E. Lugares e culturas na disciplina escolar Biologia: examinando as práticas experimentais nos processos de ensinar e aprender. In: Anais... XIV Encontro Nacional de Didática e Prática de Ensino - ENDIPE. Porto Alegre, 2008.

SILVA, M. C. F.; SOUZA, K. A.; RIBEIRO, T. C. S.; MATOS, P. N.; GALIETA, T. Relato de uma atividade teórico-prática sobre histologia no ensino médio realizada no âmbito do PIBID. In: Anais... VII Encontro Nacional de Ensino de Biologia / I Encontro Regional de Ensino de Biologia Norte. Belém, PA: SBEnBio, 2018.

STUART, R. C.; MARCONDES, M. R. As habilidades desenvolvidas por alunos do ensino médio de química em uma atividade experimental investigativa. In: Anais... VI Encontro Nacional de Pesquisa em Educação em Ciências. Belo Horizonte: ABRAPEC, 2007. 
Recebido: 16 nov. 2019

Aprovado: 22 mai. 2020

DOI: $10.3895 /$ actio.v5n2.11286

Como citar:

GALIETA, T. Contribuições de atividades prático-experimentais para a formação de professores: reflexões a partir de um projeto de iniciação à docência em biologia. ACTIO, Curitiba, v. 5, n. 2, p. 1-23, mai./ago. 2020.

Disponível em: <https://periodicos.utfpr.edu.br/actio>. Acesso em: XXX

Correspondência:

Tatiana Galieta

Rua Dr. Francisco Portela, n. 1470, Patronato, São Gonçalo, RJ, Brasil.

Direito autoral: Este artigo está licenciado sob os termos da Licença Creative Commons-Atribuição 4.0

Internacional.

(c) (i) 